\title{
HEALTH SYSTEM RESILIENCE: REVIEW OF THE CONCEPT AND A FRAMEWORK FOR ITS UN- DERSTANDING
}

\author{
Maria Rohova, Stefka Koeva \\ Department of Health Economics and Management, Faculty of Public Health, \\ Medical University-Varna, Bulgaria.
}

\begin{abstract}
:
Resilience and capacity for resilience is an emerging concept in health system governance and a comparatively new dimension of health systems performance, an area in which health policy faces problems and challenges not sufficiently explored. Although it has been attracting significant attention, the conceptualization of health system resilience that goes beyond the normative interpretation of the construct is still not well developed.

The aim of the study is to review the concept of health system resilience and to extend the existing understanding in the context of health system governance. Drawing on the results of our review, we propose a framework for health system resilience.

The review shows that resilience is grasped as a property in the context of the health system as a complex adaptive system. Moreover, resilience is contextual; it is highly context-dependent and path-dependant. It refers to the dynamics of the system and reflects the changing environment. Resilience is interpreted as the capacity of the health system to resist shocks and disturbances and to anticipate, withstand and respond to crises, i.e. to maintain its core functions, which is related to the abilities to absorb shocks and stresses, adapt to changes and transform its structures and institutions. Our proposed framework builds on and extends the existing knowledge and core frameworks, identifying three types of mechanisms (compensatory, adaptive and transformative) that help the system to maintain short- and long-term resilience. The framework can advance the understanding of the health system resilience and guide actions to strengthen health systems.
\end{abstract}

Keywords: health system, resilience, framework, concept,

\section{BACKGROUND}

In the past decade, the international health systems agenda has included a distinctive new emphasis, that on resilience. The topic of resilience has gained significant attention among policymakers, international organizations and health system researchers, the 2008 global economic crisis $[1,2,3,4]$ and the Zica and Ebola outbreaks [5, 6, 7, 8, 9, 10] serving as a catalyst to this effect. It is already considered as an essential aspect of health system performance and strengthening [11, 12]. The COVID-19 pandemic putting enormous pressure on health and social care systems has moved the topic of resilience high onto the health policy agenda $[13,14]$.

On a broader scale, this theme has been explicitly introduced by the World Health Organisation (WHO) in its 2011 Sixty-Fourth World Health Assembly resolution stressing the need for strengthening "the resilience of the health system and society at large" in order to "prepare for and respond to disasters" [15]. Taking into account the growing number of shocks faced by all countries, the Organisation for Economic Co-operation and Development (OECD) has also taken an interest in the topic, developing Guidelines for Resilience System Analysis[16], which serve as a methodological basis for the 2018 analysis of the resilience capacity of the OECD health care systems during the "refugee crisis" [17].

At the European level, the attention to the topic has developed as part of the path towards health systems strengthening following the adoption of the Tallinn Charter Health Systems for Health and Wealth in 2008. The inclusion of the resilience theme in the 2014 European Commission Communication on Effective, Accessible and Resilient Health Systems [18] and the selection of resilience as a strategically relevant priority area with a potential for the most impact to be scrutinized and analyzed by the Expert Group on Health Systems Performance Assessment in 2019 provide evidence to the new focus on the EU agenda.

Resilience and capacity for resilience is an emerging concept in health system governance and a comparatively new dimension of health systems performance in which health policy faces problems and challenges not sufficiently explored. Although the body of literature on resilience is growing, the nature of this construct, theoretical underpinning, defining characteristics, drivers and enablers, countryspecific context, different dimensions and even less so, its operationalization, the indicators to measure the resilience capacity of the system, remain insufficiently explored [19]. The conceptualization of health system resilience that goes beyond the normative interpretation of the concept is still not well developed. A better understanding is particularly important for low and middle-income countries, whose health systems are more susceptible to shocks and stresses [14]. The high-performing health systems are still vulnerable 
to unexpected risks and crises as well, which became obvious in the light of the COVID-19 pandemic [20, 21]. The enormous pressure of coronavirus disease on health systems around the world gives particular emphasis on assessment and strengthening resilience [13] and requires scrutinizing the defining characteristics of a resilient health system.

We set out to explore how to understand and interpret the literature addressing the topic of resilience. The aim of the study is to review the concept of health system resilience and to extend the existing understanding in the context of health system governance. More specifically, we are interested in the way resilience has been defined in the health system context and the progress, which has been made in conceptualizing it. Drawing on the results of our review, we propose a framework, which is focusing on the mechanisms of health system governance to maintain resilience. We hope to facilitate the future operationalization of the concept; the proposed framework can advance the existing understanding of resilience and guide actions to strengthen health systems.

A comprehensive literature review was carried out in 2019-2020. The search strategy was devised to identify studies that focused on the theme of resilience in the context of health systems. Searches for peer-reviewed articles were conducted in the following databases: Scopus, PubMed, ScienceDirect, WHO library (Hinari). The keywords and terms used for the search were "resilience" in combination with "health crisis", "health system", and "health care". There were no period restrictions.

As this is an emerging theme in health system theory and health policy, a significant impetus to its incorporation in the existing body of health systems knowledge has been given by the international organizations and cannot be found in the peer-reviewed literature. This is why additional grey literature search was conducted using the above-mentioned terms with a focus on the international organizations' publications, documents, policy briefs, guidelines, communications, and working papers, as well as by non-governmental organizations and think tanks. Generic search engines Google Scholar and Google Advanced Search were also used to identify studies otherwise omitted.

The search results were narrowed down to studies in the English language only; readily available online; defining or describing the resilience of health systems; related explicitly to resilience as an aspect of the health system and health care performance.

After merging the databases' results, 2640 sources were produced, and 1438 records left after duplicates removal. The search results were screened by title; further selection narrowed the sources down based on reading the abstracts, followed by identifying the full-text formats of papers, which seemed relevant. A total of 1256 articles did not meet the inclusion criteria (specifically related to the health system resilience). The full-text search of the resulting 182 sources leads to the identification of 35 to be included in the review, and 11 articles were added from the reference lists of the reviewed studies.

\section{REVIEW RESULTS}

\section{Resilience concept and definitions}

The health and health system researchers have had the opportunity to build on the accumulated knowledge of the topic in domains outside healthcare and incorporate the relevant insights into the comparatively more recent field [19].

Much of the research on resilience preceding research at a system/society level concerns health resilience (or resilience for health), usually at an individual or community level, and the factors influencing it. A number of articles apply resilience to speciûc circumstances or settings. The resilience of health systems in terms of adjustment to economic crises and austerity is assessed in Thomas et al. [1]. In a similar context, but from a slightly different angle, Glonti et al. approach health resilience to the negative health outcomes and behaviours during the economic downturn [2]. Some studies explore the endurance and resilience of patients and providers coping with overburdened and dysfunctional health systems [22] or the health workers' resilience in fragile and conflict-affected health systems [23]. There are a number of studies that address health systems resilience but more as a side-track theme, peripherally to another major topic or through the lens of a specific subfield or activity such as resilience and workforce of health systems for women's, children's, and adolescents' health [24]; maternal health [25]; resilience of health services during a public health emergency [26] and the role of health ministries in low- and middle-income countries for fostering resilience in health systems [27]. Various studies examine resilience at an organizational level in the health sector [28, 29].

It is only in recent years that studies addressing resilience explicitly at a health system level have become popular. Following a review of the literature, we have selected only studies that address and analyze resilience at a society/health system level in a more holistic and consistent way. Table 1 summarises the most important findings.

Table 1. Health systems resilience concept

\begin{tabular}{|c|c|c|}
\hline Source & Definition & Key points and notes \\
\hline $\begin{array}{l}\text { Thomas et al. } \\
2013\end{array}$ & $\begin{array}{l}\ldots \text { the capacity of a health system to deal } \\
\text { with economic contraction and reorganize so } \\
\text { as to retain essentially the same policies and } \\
\text { functions. }\end{array}$ & $\begin{array}{l}\text { - Assessing the resilience of health systems in terms } \\
\text { of how they have adjusted to the economic crisis } \\
\text { under austerity. } \\
\text { - Proposing a framework with three forms of resil- } \\
\text { ience: financial, adaptive and transformative. }\end{array}$ \\
\hline
\end{tabular}




\begin{tabular}{|c|c|c|}
\hline $\begin{array}{l}\text { Kruk et al. } \\
2015 ; \\
\text { Kruk et al. } \\
2017\end{array}$ & $\begin{array}{l}\ldots \text { the capacity of health actors, institutions, } \\
\text { and populations to prepare for and effec- } \\
\text { tively respond to crises; maintain core func- } \\
\text { tions when a crisis hits; and, informed by les- } \\
\text { sons learned during the crisis, reorganize if } \\
\text { conditions require it. }\end{array}$ & $\begin{array}{l}\text { - Health systems are complex adaptive systems. } \\
\text { - Resilience is an emergent property of the health } \\
\text { system as a whole rather than a single dimension. } \\
\text { - Identifying five characteristics (dimensions) of a } \\
\text { resilient health system: awareness, diversity, self- } \\
\text { regulation, integration, and adaptation. }\end{array}$ \\
\hline $\begin{array}{l}\text { Kieny \&Dolvo } \\
2015\end{array}$ & $\begin{array}{l}\text { A resilient health system is one able to ab- } \\
\text { sorb the shock of an emergency ... and, at } \\
\text { the same time, continue to provide regular } \\
\text { health services, leaving other sectors of the } \\
\text { country fully functioning. }\end{array}$ & $\begin{array}{l}\text { - Identifying six essential elements of (Post-Ebola) } \\
\text { resilient systems: health workers; medical supplies; } \\
\text { health information system, including surveillance; } \\
\text { well-equipped health facilities (infrastructure); fi- } \\
\text { nancing; and strong public sector. }\end{array}$ \\
\hline $\begin{array}{l}\text { Ammar et al. } \\
2016\end{array}$ & $\begin{array}{l}\text {... the capacity of a health system to absorb } \\
\text { internal and external shocks and maintain } \\
\text { functional health institutions while sustain- } \\
\text { ing achievements. }\end{array}$ & $\begin{array}{l}\text { - Use an input-process-output/outcome model of a } \\
\text { health system. }\end{array}$ \\
\hline $\begin{array}{l}\text { Blanchet et al. } \\
2017\end{array}$ & $\begin{array}{l}\text { The capacity of the health system to absorb, } \\
\text { adapt and transform when exposed to a shock } \\
\text { such as a pandemic, natural disaster, armed } \\
\text { conflict or a financial crisis and still retain } \\
\text { the same control over its structure and func- } \\
\text { tions (based on Thomas et al. 2013; } \\
\text { Campbell et al. 2015). }\end{array}$ & $\begin{array}{l}\text { - The specific angle is the governance of resilience } \\
\text { based on system thinking and complexity theories. } \\
\text { - Propose a framework with three levels of resilience } \\
\text { absorptive capacity, adaptive capacity and transfor- } \\
\text { mative capacity. }\end{array}$ \\
\hline $\begin{array}{l}\text { Kieny et al. } \\
2017\end{array}$ & $\begin{array}{l}\ldots \text { the capacity of healthcare actors, institu- } \\
\text { tions and populations to prepare for and re- } \\
\text { spond to crises, maintain core functions in } \\
\text { time of crisis; and, informed by lessons learnt } \\
\text { during the crisis, reorganize if needed. }\end{array}$ & $\begin{array}{l}\text { - The angle is universal coverage. } \\
\text { - Resilience is presented explicitly as an intermedi- } \\
\text { ary goal (or dimension) of health system policies. }\end{array}$ \\
\hline $\begin{array}{l}\text { Thomas et al. } \\
2020\end{array}$ & $\begin{array}{l}\text {... the ability to prepare for, manage (absorb, } \\
\text { adapt and transform) and learn from shocks. }\end{array}$ & $\begin{array}{l}\text { - Defining resilience for operational purposes, nar- } \\
\text { rowing the focus on sudden and severe disturbances. }\end{array}$ \\
\hline
\end{tabular}

Thematically, the predominant part of the studies addresses the topic from the perspective of the health systems of the West African countries and their response to the 2014-2015 Ebola epidemic [5, 6, 7, 8, 11,30] and more recently from the perspective of health systems' response to the COVID-19 pandemic [13, 20]. Several studies explore the resilience of the health systems faced by refugee crisis [17, 31, 32, 33] or insurgencies [34] and terrorist attacks [35]. WHO approaches the resilience topic from the perspective of the small European countries and more generally in the context of the health system strengthening [12].

Although the various definitions differ in their inclusiveness and use diverse wordings, most of them (at least the most recent ones) highlight similar elements. Several broad sets of themes and key characteristics underlying resilience as an attribute of the health system and a dimension of health system performance emerge from the review:

(1) Resilience is grasped as a property in the context of health systems as complex adaptive systems. In the specialized literature, complex adaptive systems are generally described as dynamic entities, which comprise a large number of elements, each governed by its own rules, which interact with each other and influence each other $[36,37,38,39,40]$. In addition to the rules and properties intrinsic to each of the component parts, the system also exhibits emergent properties and rules independent of the individual ones, which cannot be reduced to any of them. This is what determines the system's aggregate behaviour - it cannot be derived from the behaviour of any of its parts. It produces outcomes, which are based on learning, reorganizing and adapting to the changing environment [41]. Besides the dynamic interaction of the numerous actors, there are additional salient features of complexity: non-linearity of interactions and interdependencies; uncertainty and change accepted as inevitable; openness of the health system, which is also nested within other systems; not so well defined boundaries; high level of diversity, which determines its capacity to adapt and coevolve; self-organization; ability to anticipate. Such an interpretation of health systems allows for some dose of unpredictability, sub-optimality, even a degree of chaos, but it takes into account the uncertainty of challenges, changing context and complexity of reality.

(2) Resilience is generally regarded as being tested against a variety of unfavourable/adverse conditions and disruptive events. There are some similarities 
but also differences of emphasis in the conceptualization of resilience across the different types of shocks. According to their nature, frequency and intensity, the challenges can be sudden or infrequent, acute, even catastrophic health shocks, which imply intensive risk (disease outbreak, armed conflict, climate related phenomena) [7], or day-to-day, slow and chronic stresses which weaken the resistance of the system and can have a cumulative greater effect over time [16,40]; natural(environmental disasters) or manmade (war conflict, terror attacks, economic or political crises) [1, 17, 32, 33]; exogenous (external to the health system) or endogenous (arising within the system - drug or vaccine shortages, smaller outbreaks of infectious diseases, sector-specific inadequate policies or reforms) [30, 31, 42].

(3) Health systems resilience is recognized as an ability (capacity) of the health systems to absorb disturbances, respond to crises, resume and maintain their core functions, with a minimum detriment to their performance

(4) Reflecting the developing scope, breadth and depth of the resilience conceptualization in the fields outside health, the definitions of health system resilience go beyond the simple "rebound" reaction. They include lesson learning, adaptation, reorganization, transformation of structures and operational means, if necessary [12, 30, 43].

(5) Resilience is described as scalable. An essential element of the conceptualization of resilience in the health, healthcare and health systems context is that it exists at different levels or scales, can be found at systems of various sizes (individual, household, local, community, sub-national, national/society) [38]. This element of the conceptualization, which encompasses the whole health system and which is primarily the subject of the present analysis, is in alignment with the systems thinking and the consideration of reality as an interaction of complex systems of different sizes, affecting each other's performance, however, the different ranges of scales having their own attributes and the shift from one scale to another being non-automatic and non-linear [42].

(6) Resilience is contextual. Health system properties are highly context-dependent and path-dependent. The way different agents interact and respond to adversary events is specific for the particular community/population, set of structures and changing the environment [8]. This is a complex construct whose meaning may be highly influenced by the already existing configuration of relationships, circumstances, cultural legacy, agency, power and trust in the system. The present behaviour of the system is profoundly shaped by its history and developed relationships within it and with the other systems. Framing resilience requires taking into account the existing general setting and identifying the system's capacities, strengths and weaknesses.

\section{System-level resilience frameworks}

Insights generated by addressing the complex adaptive nature of health systems and analyses predominantly of responses to the Ebola and some other crises have helped researchers develop analytical frameworks. Several frameworks have been proposed, which consistently recur in the literature.

The "capacity-oriented" framework describes resilience as an emerging property of health systems as composed of three structuring elements: absorptive, adaptive, and transformative capacity [32, 40, 42, 44]. The absorptive capacity is identified with the immediate coping and responsive reaction to an emergency; it is believed to preserve the stability and structure of the system. The adaptive capacity allows the system to recover from the shock, mitigate damages, adjust and even take advantage of opportunities; it implies the ability to learn from experience and change and gives flexibility to the system. The transformative capacity allows for the anticipation of future threats; it is associated with significant long-term changes in the structure of the system. WHO structures the above mentioned capacities into four groups: adaptive (the ability to adjust to disturbances); absorptive (the capacity to cope with and recover from perturbations); anticipatory (the capacity to predict threats and proactively reduce vulnerability); and transformative (the ability to transform the structure and functioning to better address future changes and challenges) [12].

An adaptation of the capacity-oriented framework but from a specific governance perspective has been put forward by Blanchet et al. [42]. This framework, adopting the complex systems approach, integrates the three capacity levels described above: absorptive, adaptive and transformative with four interlinked dimensions to manage resilience: knowledge ("capacity to collect, integrate and analyze different forms of knowledge and information"); uncertainties ("ability to anticipate and cope with uncertainties and surprises"); interdependency ("capacity to manage interdependence: to engage effectively with and handle multiple- and cross-scale dynamics and feedbacks"); and legitimacy ("capacity to build or develop legitimate institutions that are socially accepted and contextually adapted").

The second five-dimensional framework is put forward by Kruk et al. [7] and is based on Rodin's [45] five characteristics of resilience: awareness (the system possesses the capacity, expertise and robust surveillance networks to capture warning signals and detect potential threats and challenges, analyze and interpret them and develop appropriate emergency response); diversity (broadbased provision of services and opportunities for treatment, appropriate health worker training, facilities, surveillance systems, diverse approaches to contain the threats); self-regulation (the capacity to identify the threat and respond in a flexible and timely manner); integration (the ability to bring together various actors, institutions, sectors, plans for the containment of the risky situation and curbing the adverse effects); and adaptability (the ability to adjust and change in response to the challenges). Kruk et al. extend and suggest an operationalization of the construct by proposing a health system index with 25 indicators, balancing slow and fast drivers, to measure resilience [30]. Kruk's five-dimensional framework has been adopted and applied descriptively to 
analyze and evaluate resilience in particular situations in specific health systems $[9,35]$.

The third type of framework is based on the WHO model of health system performance. In order to capture and evaluate both the specificity of the shock and the response determined by the properties of the health system, Ammar et al. approach the study of the Lebanese health system resilience coping with the Syrian refugee crisis by employing an input-process-output/outcome model [31]. The health system concept adopted in the study is based on the WHO definition and corresponding building blocks, covering major functions of the health system such as financing, service delivery, human resources and governance [46]. The outcomes, which are accepted to measure the performance of the system, include utilization, service coverage, prevention of infection outbreaks, morbidity and mortality rates. Employing a health system approach to the more general theme of crisis management, Bayntun et al. [47] also draw on the WHO's six health system building blocks to analyze the health systems preparedness and response to disasters. Similarly, in their study of the resiliency and people-centeredness of the health systems of Asia, Legido-Quigley et al. define resilience as "a capacity to recover from and absorb shocks and sustain gains, but also to promote stronger health systems" and assess resilience from the perspective of a set of core functions of health systems, including governance, service delivery, provision of services, human and physical resources, and financing [48]. The framework through which OXFAM has analyzed the health systems resilience of the countries struck by the Ebola crisis is founded on six elements: trained health workers; health information systems and appropriate surveillance; wellequipped health facilities (infrastructure); adequate financing, and strong service delivery [5]. Examining empirical evidence of how health systems responded to past shocks, Hanefeld et al. identify " 3 plus 2" critical dimensions of resilience: three core dimensions corresponding to three health systems functions(health information systems, funding/financing mechanisms, and health workforce), intersecting with two cross-cutting aspects (governance and predominant values) [10].

\section{The proposed framework}

The framework for health system resilience that we put forward steps on the models outlined above, incorporating and adapting some of their approaches and elements and can be seen as an attempt to extend and further develop the existing constructs. It depicts our interpretation of resilience as the capacity of the health system to resist everyday shocks and disturbances and to anticipate, withstand and respond to crises, i.e. to maintain its core functions, which is related to the abilities to absorb shocks and stresses, adapt to changes and transform its structures and institutions.

The proposed framework (fig. 1) builds on the " $\mathrm{ca}$ pacity-oriented" framework, including widely accepted elements: absorptive, adaptive and transformative abilities of the system $[42,44]$. The framework conceptualizes resilience from the health system governance perspective and sets out core mechanisms to achieve and maintain the resilience of the system.

The framework includes three types of mechanisms, which help the system to achieve and maintain short- and long-term resilience:

(1) Stress/shocks absorbers - these are compensatory mechanisms, which serve as built-in stabilizers of the system. They facilitate the absorption of everyday stresses and shocks experienced by health care, which can originate within the system or outside of it. Examples of such absorbers are the protocols for vaccinations in cases of occasional epidemic outbreaks or the prescribed organization of medical care in cases of natural or manmade disasters. Such mechanisms are usually regulated by national legislation and help the health system to withstand and absorb the most common stresses and shocks without severe disturbances of its functions.

(2) Context adjustors - these are adaptive mechanisms, which suppose reactive adaptation to changes in the system environment. The health system reacts to modifications in the context in which it functions, and in this case, the reaction follows a somewhat "tailored" approach or flexible adaptation to the new conditions. The changes in the environment can influence the system with a different intensity, i.e. can be interpreted as stresses, shocks or even crises. What matters, however, is that the health system is not prepared to absorb the disturbances and, therefore, reacts to changes with new models of care or new structures, for example, which subsequently can be regulated through legislative changes.

(3) System transformers - they are related to the ability of the system to anticipate crises and to undertake proactive measures in order to prevent damaging consequences. The transition mechanisms imply proactive transformation or substantial reforms in the system, which may require an approach that is more radical. The system does not react but forestalls crises usually caused by outside circumstances or within the context. Examples of such reforms could be the change in health coverage or a reorganization of long-term care to withstand the demographic ageing.

The introduction of the latter mechanisms can be a lengthy process, in the course of which a new configuration of stress/shocks absorbers should be ensured to guarantee everyday resilience, that is, the flexibility of the system to react and respond to more immediate stressors and disruptive events. However, in some instances, the process of transformation could be disturbed, and the compensatory and adaptive mechanisms may harm the resilience instead of maintaining it. This could happen if absorption and adaptation restrain the transformation of the health system: the system resists stresses, shocks and crises (absorbs or adapts), preventing a 'healthy' transformation. Such a system can be considered 'quasi-resilient' as absorption and adaptation facilitate everyday resilience, but in the absence of genuine transformation (reforms), this may hamper long-term resilience. 
Fig. 1. Framework for health system resilience

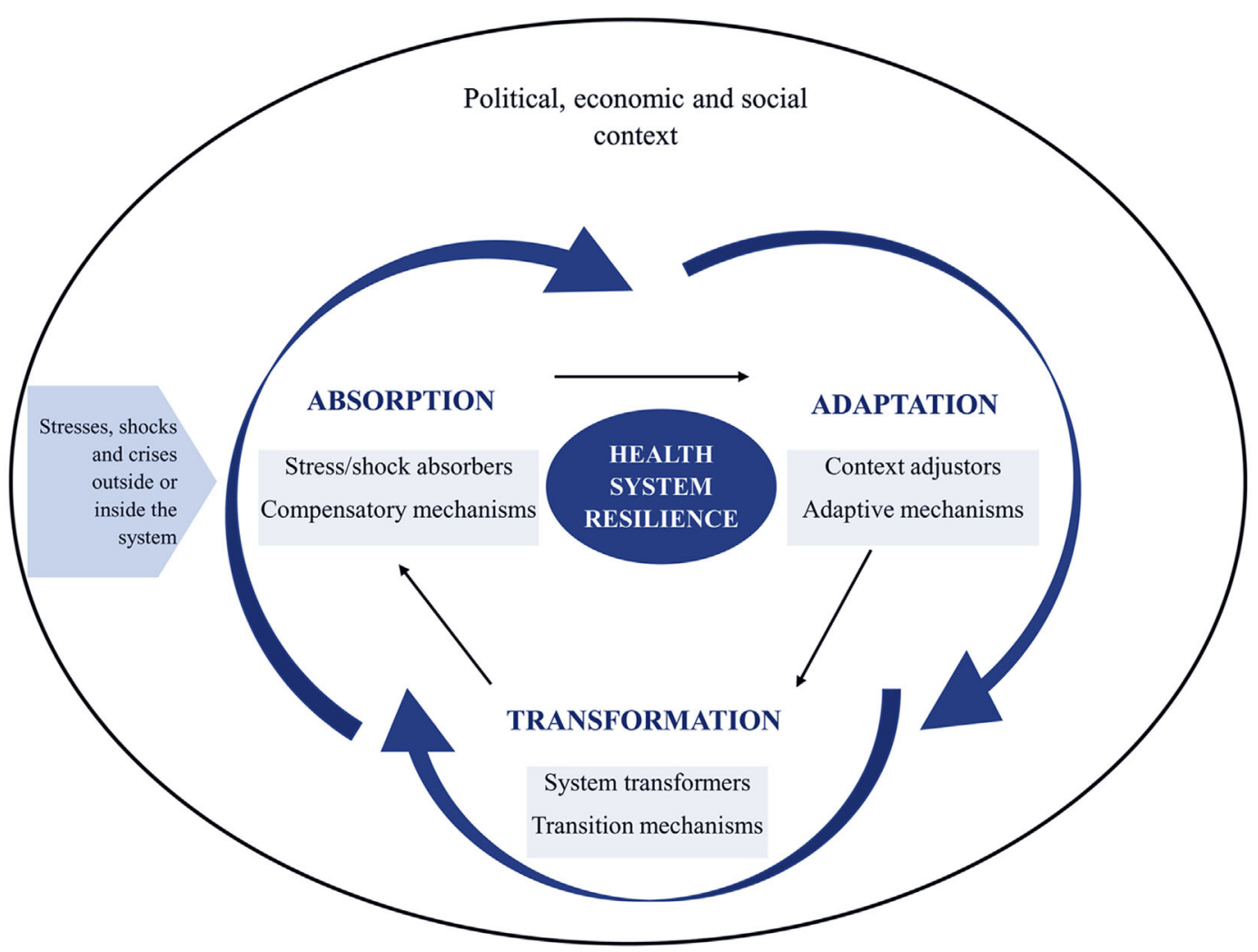

\section{CONCLUSION}

The resilience agenda has gathered momentum among policymakers and researchers since the 2008 economic crisis, Zica and Ebola outbreaks, but the COVID-19 pandemic can be seen as an unprecedented test of health system preparedness for sudden and severe shocks and crises, revealing the shortcomings of response plans and the need for greater resilience. Resilience matters now more than ever and has become a critical prerequisite for a wellperforming health system capable of maintaining its core functions and resisting unexpected shocks and crises. In the light of the COVID-19 pandemic, the number of studies discussing preparedness of the health systems and effectiveness of countries' responses has been rapidly growing; however, in the long term, the assessment and strengthening of resilience remain a challenge, which will trigger the future research.

Research on health system resilience is still in the explorative stage, especially the way it is modelled and translated into indicators to be tested. Resilience-related research is moving from purely conceptual thinking to a search for operational ways and means of enhancing resilience at the individual, community and system levels. Research challenges include efforts to reach common ground on the understanding of the concept in its entirety or, at least, of the critical ingredients over which there is a considerable agreement in the research community.

Developing a framework for system performance and its assessment is a challenging task, but it is a step forward in the right direction. The examination of the concept, its underlying meaning, aspects, framing is a necessary first stage. Given the limitations and insufficient attempts to operationalize it in the scholarly literature, the selection of indicators will be an achievement. At this point, the very discussion of the measurability of resilience and the extent to which it can be assessed in advance before a major shock remains justified.

\section{Abbreviation:}

OECD - Organisation for Economic Co-operation and Development

WHO - World Health Organisation

\section{REFERENCES:}

1. Thomas S, Keegan C, Barry S, Layte R, Jowett M, Normand C. A framework for assessing health system resilience in an economic crisis: Ireland as a test case. BMC Health Serv Res. 2013 Oct 30;13:450. [PubMed]

2. Glonti K, Gordeev VS, Goryakin Y, Reeves A, Stuckler D, McKee M, et al. A systematic review on health resilience to economic crises. PLoS One. 2015 Apr 23;10(4):e0123117. [PubMed]

3. Witter S, Hunter B. Resilience of health systems during and after crises - what does it mean and how can it be enhanced? ReBUILD Research Pro- gramme Consortium; 2017. [Internet]

4. Massuda A, Hone T, Leles FAG, de Castro MC, Atun R. The Brazilian health system at crossroads: progress, crisis and resilience. BMJ Glob Health. 2018 Jul 3;3(4):e000829. [PubMed]

5. Kamal-Yanni M. Never again. Building resilient health systems and 
learning from the Ebola crisis. Oxford: OXFAM; 2015. [Internet]

6. Kieny MP, Dovlo D. Beyond Ebola: a new agenda for resilient health systems. Lancet. 2015 Jan 10; 385(9963):91-2. [PubMed]

7.Kruk ME, Myers M, Varpilah ST, Dahn BT. What is a resilient health system? Lessons from Ebola. Lancet. 2015 May 9;385(9980):1910-2. [PubMed]

8. Martineau FP. People-centred health systems: building more resilient health systems in the wake of the Ebola crisis. Int Health. 2016 Sep; 8(5):307-9. [PubMed]

9. Ling EJ, Larson E, MacAuley RJ, Kodl Y, Vandebogert B, Baawo S, Kruk ME. Beyond the crisis: did the Ebola epidemic improve resilience of Liberia's health system? Health Policy Plan. 2017 Nov 1;32(suppl_3): iii407. [PubMed]

10. Hanefeld J, Mayhew S, LegidoQuigley H, Martineau F, Karanikolos $\mathrm{M}$, Blanchet K, et al. Towards an understanding of resilience: responding to health systems shocks. Health Policy Plan. 2018 Apr 1;33(3):355367. [PubMed]

11. Kutzin J, Sparkes SP. Health systems strengthening, universal health coverage, health security and resilience. Bull World Health Organ. 2016 Jan 1;94(1):2. [PubMed]

12. World Health Organisation/ WHO. Regional Office for Europe. Building resilience: a key pillar of Health 2020 and the Sustainable Development Goals: examples from the WHO Small Countries Initiative. Geneva: WHO; 2017. [Internet]

13. Thomas S, Sagan A, Larkin J, Cylus J, Figueras J, Karanikolos M. Strengthening health system resilience: Key concepts and strategies. Health system and policy analysis. Policy brief 36 . Copenhagen: WHO Regional Office for Europe, European Observatory on Health Systems and Policies; 2020. [Internet]

14. Grimm PY, Oliver S, Merten S, Han WW, Wyss K. Enhancing the understanding of resilience in health systems of low- and middle-income countries: A qualitative evidence synthesis. Int J Health Policy Manag. 2021 Jan 16 (in press);1-13. [PubMed]

15. World Health Organisation/
WHO. World Health Assembly. Resolution 64.10. Strengthening national health emergency and disaster management capacities and resilience of health systems. WHO; 2011. [Internet]

16. Organisation of Economic Cooperation and Development/OECD. Guidelines for resilience systems analysis. Paris: OECD Publishing; 2014. [Internet]

17. Organisation of Economic Cooperation and Development/OECD. How resilient were OECD health care systems during the "refugee crisis"? Migration Policy Debates, No. 17. Paris: OECD Publishing; 2018.

18. European Commission. Communication on effective, accessible and resilient health systems. Brussels: European Commission; 2014; COM (2014) 215 final. [Internet]

19. Koeva S, Rohova M. Health system resilience: Concept development. J of IMAB. 2020 Jul-Sep; 26(3): 3251-3258. [Crossref]

20. Bcheraoui CE, Weishaar $\mathrm{H}$, Pozo-Martin F, Hanefeld J. Assessing COVID-19 through the lens of health systems' preparedness: time for a change. Global Health. 2020 Nov 19;16(1):112. [PubMed]

21. Legido-Quigley H, Asgari N, Teo YY, Leung GM, Oshitani H, Fukuda $\mathrm{K}$ et al. Are high-performing health systems resilient against the COVID-19 epidemic? Lancet. 2020 Mar 14;395(10227):848-850. [PubMed]

22.Eyles J, Harris B, Fried J, Govender V, Munyewende P. Endurance, resistance and resilience in the South African health care system: case studies to demonstrate mechanisms of coping within a constrained system. BMC Health Serv Res. 2015 Sep 29; 15:432. [PubMed]

23. Witter S, Wurie H, Chandiwana P, Namakula J, So S, Alonso-Garbayo A, et al. How do health workers experience and cope with shocks? Learning from four fragile and conflict-affected health systems in Uganda, Sierra Leone, Zimbabwe and Cambodia. Health Policy Plan. 2017 Nov 1;32(suppl_3):iii3-13. [PubMed]

24. Campbell J, Cometto G, Rasanathan K, Kelley E, Syed S, Zurn $\mathrm{P}$, et al. Improving the resilience and workforce of health systems for women's, children's, and adolescents' health. BMJ. 2015 Sep 14;351:h4148. [PubMed]

25. Kruk ME, Kujawski S, Moyer CA, Adanu RM, Afsana K, Cohen J et al. Next generation maternal health: external shocks and health system innovations. Lancet. 2016 Nov 5;388(10057):2296-2306. [PubMed]

26. Shrivastava SR, Shrivastava PS, Ramasamy J. Ensuring health system resilience following a public health emergency. Ann Trop Med Public Health. 2017;10:282-3. [Crossref]

27. Naimoli J, Saxena S. Realizing their potential to become learning organizations to foster health system resilience: opportunities and challenges for health ministries in low- and middle-income countries. Health Policy Plan. 2018 Dec 1;33(10):1083-1095. [PubMed]

28. Gilson L, Barasa E, Nxumalo N, Cleary S, Goudge J, Molyneux S, et al. Everyday resilience in district health systems: emerging insights from the frontlines in Kenya and South Africa. BMJ Glob Health. 2017 Jun 2;2(2):e000224. [PubMed]

29. Barasa E, Mbau R, Gilson L. What is resilience and how can it be nurtured? A systematic review of empirical literature on organizational resilience. Int J Health Policy Manag. 2018 Jun 1;7(6):491-503. [PubMed]

30. Kruk ME, Ling EJ, Bitton A, Cammett M, Cavanaugh K, Chopra M, et al. Building resilient health systems: a proposal for a resilience index. $B M J$. 2017 May 23;357:j2323. [PubMed]

31. Ammar W, Kdouh O, Hammoud R, Hamadeh R, Harb H, Ammar Z, et al. Health system resilience: Lebanon and the Syrian refugee crisis. J Glob Health. 2016 Dec;6(2):020704. [PubMed]

32. Razum O, Bozorgmehr K. Refugee migration to Germany: did the health system show resilience? Eur J Public Health. 2017 Nov;27(suppl_3). [Crossref]

33. Alameddine M, Fouad FM, Diaconu K, Jamal Z, Lough G, Witter S, Ager A. Resilience capacities of health systems: accommodating the needs of Palestinian refugees from Syria. SocSci Med. 2019 Jan;220:2230. [PubMed]

34. Ager AK, Lembani M, Mohammed A, Ashir GM, Abdulwahab A, de 
Pinho $\mathrm{H}$, et al. Health service resilience in Yobe state, Nigeria in the context of the Boko Haram insurgency: a systems dynamics analysis using group model building. Confl Health. 2015 Oct 5;9:30. [PubMed]

35. Ridde V, Lechat L, Meda IB. Terrorist attack of 15 January 2016 in Ouagadougou: how resilient was Burkina Faso's health system? BMJ Glob Health. 2016 Jul 7;1(1): e000056. [PubMed]

36. Plsek PE, Greenhalgh T. Complexity science: the challenge of complexity in health care. BMJ. 2001 Sep 15;323(7313):625-8. [PubMed]

37. Savigny D, de. Adam T. (Eds.). Systems thinking for health systems strengthening. Alliance for Health Policy and Systems Research, WHO; 2009. [Internet]

38. Pourbohloul B, Kieny MP. Complex systems analysis: towards holistic approaches to health systems planning and policy. Bull World Health Organ. 2011 Apr 1;89(4):242. [PubMed]

39. Paina L, Peters DH. Understanding pathways for scaling up health services through the lens of complex adaptive systems. Health Policy Plan. 2012 Aug;27(5):365-373. [PubMed]
40. Barasa EW, Cloete K, Gilson L. From bouncing back, to nurturing emergence: reframing the concept of resilience in health systems strengthening. Health Policy Plan. 2017 Nov 1;32(suppl_3):iii91-4. [PubMed]

41.Holland JH. Complex adaptive systems. Daedalus. 1992;121(1):1730. [Internet]

42. Blanchet $K$, Nam SL, Ramalingam B, Pozo-Martin F. Governance and capacity to manage resilience of health systems: towards a new conceptual framework. Int J Health Policy Manag. 2017 Aug 1;6(8):431-5. [PubMed]

43. Fridell $M$, Edwin $S$, von Schreeb J, Saulnier DD. Health system resilience: What are we talking about? A scoping review mapping characteristics and keywords. Int $J$ Health Policy Manag. 2020 Jan 1;9(1):6-16. [PubMed]

44. Bene C, Godfrey Wood R, Newsham A, Davies M. Resilience: new utopia or new tyranny? Reflection about the potentials and limits of the concept of resilience in relation to vulnerability reduction programmes. Brighton: Institute of Development Studies; 2012. [Internet]

45. Rodin J. The resilience divi- dend: being strong in a world where things go wrong. New York: Public Aûairs; 2014

46. World Health Organisation/ WHO. Everybody's business: strengthening health systems to improve health outcomes: WHO's framework for action. Geneva: WHO; 2007. [Internet]

47. Bayntun C, Rockenschaub G, Murray V. Developing a health system approach to disaster management: A qualitative analysis of the core literature to complement the WHO Toolkit for assessing health-system capacity for crisis management. PLoSCurr. 2012 Aug 22;4: e5028b6037259a. [PubMed]

48. Legido-Quigley H, AsgariJirhandeh N (Eds.). Resilient and people-centred health systems: progress, challenges and future directions in Asia. New Delhi: World Health Organization, Regional Office for SouthEast Asia; 2018 [Internet]

49. Kieny MP, Bekedam H, Dovlo D, Fitzgerald J, Habicht J, Harrison G et al. Strengthening health systems for universal health coverage and sustainable development. Bull World Health Organ. 2017 Jul 1;95(7):537-9. [PubMed]

Please cite this article as: Rohova M, Koeva S. Health system resilience: Review of the concept and a framework for its understanding. J of IMAB. 2021 Oct-Dec;27(4):4060-4067. DOI: https://doi.org/10.5272/jimab.2021274.4060

Received: 04/03/2021; Published online: 25/10/2021

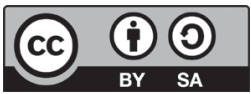

Address for correspondence:

Maria Rohova

Department of Health Economics and Management, Faculty of Public Health, Medical University - Varna,

55, Marin Drinov Str., Varna, Bulgaria

E-mail: mariarohova@abv.bg 